\title{
Cerebral Injury and Neurodevelopmental Outcome in Twin-Twin Transfusion Syndrome
}

\author{
Jeanine M. M. van Klink • Hendrik M. Koopman • \\ Sylke J. Steggerda • Dick Oepkes • Monique Rijken • \\ Enrico Lopriore
}

Published online: 28 July 2013

(C) Springer Science+Business Media New York 2013

\begin{abstract}
Twin-twin transfusion syndrome (TTTS) is a severe complication of monochorionic twin pregnancies associated with high perinatal mortality and morbidity rates. Management in TTTS is a major challenge for obstetricians and neonatologists. Twins with TTTS often are born prematurely after an extremely distressing and highly hazardous fetal period. In addition to complications associated with prematurity, surviving twins with TTTS are at increased risk for other complications, including neurological, cardiovascular, renal, and hematologic morbidity. Follow-up studies report varying rates of cerebral palsy and long-term neurodevelopmental impairment. This review focuses on the cerebral injury during the neonatal period as well as long-term neurodevelopmental outcome of TTTS survivors.
\end{abstract}

Keywords Twin-twin transfusion syndrome $\cdot$ Monochorionic twins · Laser surgery · Amnioreduction · Cerebral injury · Neurodevelopmental outcome

\footnotetext{
J. M. M. van Klink

Department of Pediatrics, Division of Neonatology, Leiden, The Netherlands

H. M. Koopman • D. Oepkes

Clinical Psychology, Faculty of Social Sciences, Leiden University, Leiden, The Netherlands
}

S. J. Steggerda $\cdot$ M. Rijken $\cdot$ E. Lopriore

Division of Fetal Medicine, Department of Obstetrics, Leiden

University Medical Centre, Leiden, The Netherlands

E. Lopriore $(\varangle)$

Department of Pediatrics, Leiden University Medical Center, J6-S, Albinusdreef 2, 2333, ZA Leiden, The Netherlands

e-mail: e.lopriore@lumc.nl

\section{Introduction}

Twin-twin transfusion syndrome (TTTS) is a severe complication of monochorionic twin pregnancies, which results from unbalanced inter-twin blood transfusion through placental vascular anastomoses. TTTS is characterized by the presence of oligohydramnion in the donor twin and polyhydramnion in the recipient twin. If left untreated, TTTS is associated with very high perinatal mortality and morbidity rates. Recent developments in prenatal care strategies and management options for patients with TTTS resulted in a significant decrease in perinatal mortality rates. Nevertheless, TTTS remains one of the most lethal conditions in perinatal medicine and the optimal management is still a major challenge for both obstetricians and neonatologists.

As perinatal survival in TTTS improves, attention is shifting towards short- and long-term outcome in surviving children. Because monochorionic twins often are delivered prematurely, twins are at risk for morbidity associated with prematurity, such as respiratory distress syndrome, chronic lung disease, necrotizing enterocolitis, and cerebral injury, including intraventricular hemorrhage (IVH) and periventricular leukomalacia (PVL). In addition, TTTS survivors are at risk for other complications, including atypical cerebral lesions (e.g., arterial stroke), cardiac morbidity, renal failure, and hematologic disorders. Rare complications, such as hypoxic-ischemic lesions to limbs or intestines, amniotic band syndrome, and congenital skin loss, also have been reported in TTTS survivors. An increasing number of studies in TTTS survivors are gradually shedding more light on the wide range of morbidity associated with TTTS.

This review will focus on the short-term neurological outcome and cerebral injury and on long-term neurodevelopmental outcome in TTTS-survivors treated with either amnioreduction or laser surgery. 


\section{Short-Term Neurological Outcome and Cerebral Injury in TTTS Survivors}

Several studies report an increased risk of cerebral injury and neurologic morbidity in TTTS. Major cerebral lesions detected in TTTS include cystic PVL), cerebral white-matter cysts, severe IVH ( $\geq$ grade III), ventricular dilatation, cerebral atrophy, and arterial ischemic stroke [1,2]. In addition, sporadic reports of TTTS cases associated with vein of Galen malformation or polymicrogyria have been published $[3,4]$. Minor lesions, such as subependymal pseudocysts and lenticulostriate vasculopathy, also have been described in monochorionic twins with TTTS [1]. The exact pathogenesis of cerebral injury in TTTS remains unclear and is probably multifactorial of origin. Cerebral injury may result from antenatal injury and/or postnatal injury, partly due to extreme prematurity, an important risk factor for cystic PVL and IVH. Antenatal injury may result from impaired cerebral perfusion due to hemodynamic imbalance and inter-twin shifts of blood through the vascular anastomoses, leading to hypoxic-ischemic insults. The exact timing of antenatal cerebral injury in TTTS is not clear. As shown in several imaging studies, cerebral lesions in TTTS may occur before laser surgery and can be detected before fetoscopic intervention using fetal ultrasound or fetal MRI [5]. However, cerebral injury also may occur during or after laser treatment. Further imaging studies are required to gain more insight in the etiology and timing of cerebral injury. Better understanding may lead to adaptation of management protocols and eventually improve the outcome in survivors.

Donors and recipients in TTTS appear to be equally at risk for cerebral injury [1]. Hypoxic-ischemic damage caused by cerebral hypoperfusion is probably the main cause for cerebral injury in donor twins, whereas hyperviscosity and polycythemia causing vascular sludging may be an important cause for cerebral injury in recipient twins. TTTS has been shown to be the main risk factor associated with perinatal arterial strokes in preterm neonates [6]. Arterial stroke events have been shown to occur mainly in recipients, involving usually the left middle cerebral artery [1]. Although the etiology of the focal ischemic stroke in the recipient is still obscure, it could theoretically be related to sludging of polycythemic blood, hypoxic-ischemia, and/or coagulation disorders [7].

Few studies have reported on the incidence of cerebral lesions in TTTS. The incidence varies greatly between the studies, ranging from $3 \%$ to $41 \%[1,8,9]$. Several methodological differences may explain this high discrepancy in results, such as different regimens of ultrasound scans, definitions of abnormality on cranial ultrasound, and discordances in number of patients included in each study. Most studies on cerebral injury in TTTS are limited by small numbers of included neonates and lack of a control group preventing accurate assessments and interpretation of the results. In addition, a restricted ultrasound regimen may lead to an underestimation of adverse outcome in TTTS survivors [10]. As previously shown, the detection of cystic PVL is known to be less reliable when only a few scans are performed during the neonatal period, and up to one third of severe cerebral lesions may then be missed [11].

Cerebral injury is reported to occur less frequently in TTTS survivors treated with laser surgery than with serial amnioreduction [8]. Importantly, this conclusion is based on the only randomized trial by Senat et al., which compared both treatments. Infants in the laser group had a lower incidence of cystic PVL than in the amnioreduction group, $6 \%(8 / 144)$ vs. $14 \%(20 / 140)$, respectively $(p=0.02)$ [8]. Of note, the definition of cystic PVL was restricted to the most severe cases of leukomalacia with very large cysts ( $\geq$ grade III), suggesting that the true incidence of cystic PVL (including grade II) in this study was even higher in both groups. In addition, the reported incidence was calculated using the total number of fetuses instead of the total number of live-born infants in whom a cranial ultrasound was performed.

The incidence and type of cerebral injury in TTTS survivors treated with amnioreduction or laser surgery reported in the literature are described in the two subchapters below and summarized in Tables 1 and 2. Of note, the extreme heterogeneity between the studies (in terms of different definitions for cerebral injury, different scan regimens, and various other methodological discordances), precluded the possibility of adding up all the numbers and prevented the calculation of an overall incidence.

\section{Cerebral Injury in TTTS Treated with Amnioreduction}

The reported incidence of cerebral injury after amnioreduction ranges from $5 \%$ to $38 \%$ (Table 1). Denbow et al. reported on neonatal cranial ultrasound findings in 17 TTTS pregnancies treated with amnioreduction. Three infants died before cranial ultrasound could be performed [12]. The incidence of severe cerebral injury in the remaining 31 infants was $16 \%(5 / 31)$. Four infants had cystic PVL and one infant had a major right temporoparietal cerebral infarct.

In a study from Hecher, $18 \%$ (8/44) of surviving neonates had an abnormal ultrasound scan [13]. Abnormal scans included cystic PVL, IVH $\geq$ grade III, parenchymal defects and microcephaly, but further details were not reported.

Cincotta et al. reported the outcome in a similar small study in 17 consecutive TTTS pregnancies of which 12 were treated with serial amnioreduction [14]. The incidence of severe cerebral injury in live-born infants was $17 \%(5 / 29)$. Three infants had cystic PVL and two infants had cerebral atrophy.

The largest study reporting on the incidence of cerebral injury in TTTS treated with amnioreduction is from a national survey of 112 TTTS cases in perinatal centers in Australia and 
Table 1 Cerebral injury in TTTS treated conservatively (with or without amnioreduction)
*The denominator is the total number of fetuses (and not the number of live-born infants).

\begin{tabular}{|c|c|c|}
\hline Author, year & Cerebral injury \% $(\mathrm{n} / \mathrm{N})$ & Comments \\
\hline Denbow 1998 [12] & $16 \%(5 / 31)$ & $\begin{array}{l}\text { Cystic PVL }(n=4) \text {; right temporoparietal cerebral infarct } \\
\quad(n=1)\end{array}$ \\
\hline Hecher 1999 [13] & $18 \%(8 / 44)$ & $\begin{array}{l}\text { Cystic PVL, IVH } \geq \text { grade III and parenchymal defect } \\
\text { (no further details on exact numbers) }\end{array}$ \\
\hline Cincotta $2000[14]$ & $17 \%(5 / 29)$ & Cystic PVL $(n=3)$; cerebral atrophy $(n=2)$ \\
\hline Mari 2000 [7] & $5 \%(3 / 42)$ & Cystic PVL $(n=2)$; multilocular encephalomalacy $(n=1)$ \\
\hline Dickinson 2000 [15] & $27 \%(38 / 139)$ & $\begin{array}{l}\text { Cystic PVL }(n=15) ; \text { porencephalic cysts }(n=2) ; \\
\text { ventriculomegaly }(n=8) ; \text { IVH } \geq \text { grade II }(n=17) ; \\
\text { calcification of the thalami }(n=1)\end{array}$ \\
\hline Haverkamp 2001 [21] & $22.5 \%(9 / 40)$ & $\mathrm{IVH} \geq$ grade III $(n=3) ;$ cystic PVL $(n=5) ; \operatorname{infarct}(n=1)$ \\
\hline Quintero 2003 [17] & $18 \%(13 / 130)$ & No details provided \\
\hline Hyodo 2003 [20] & $15 \%(5 / 34)$ & Cystic PVL $(n=5)$ \\
\hline Lopriore 2003 [2] & $21 \%(6 / 29)$ & $\mathrm{IVH} \geq$ grade III $(n=3) ;$ ventriculomegaly $(n=3)$ \\
\hline Senat 2004 [8] & $19 \%(28 / 140)^{*}$ & Cystic PVL $\geq$ grade III $(n=20)$, IVH $\geq$ grade III $(n=8)$ \\
\hline Adegbite 2005 [18] & $38 \%(15 / 40)$ & White matter lesions $(n=15)$ \\
\hline Lenclen 2007 [19] & $38 \%(11 / 38)$ & Cystic PVL $(n=9)$, IVH $\geq$ grade III $(n=5)$ \\
\hline Range & $5-38 \%$ & \\
\hline
\end{tabular}

New Zealand [15]. Of the 139 live born infants studied with cranial ultrasound, 38 (27\%) had abnormalities of which $11 \%$ $(15 / 38)$ had cystic PVL and $5 \%$ (2/38) had porencephalic cysts.

Mari et al. reported the outcome in 33 TTTS pregnancies treated with serial amnioreduction [16]. Of the 51 live born neonates, 3 (6\%) had cystic PVL or multilocular encephalomalacy. All three cases were recipients.

We also reported a series of 33 TTTS pregnancies, treated either with amnioreduction $(n=18)$ or conservatively $(n=11)$. Severe cerebral injury was detected in 6 of the 29 neonates (21 \%) in whom a cranial ultrasound scan was performed (IVH $\geq$ grade III, $n=3$; severe ventricular dilatation $>97$ th centile, $n=3$ ) [2].

Quintero et al. reported an incidence of neurologic morbidity in $18 \%(23 / 130)$ of TTTS survivors after amnioreduction
[17]. The definition of neurologic morbidity was a mix of ultrasound diagnoses (PVL, ventriculomegaly, $\mathrm{IVH} \geq$ grade III) and clinical diagnoses (cerebral palsy, microcephaly). Besides the reported raw values on the overall incidence, no further details were reported. Whether cranial ultrasound scans were performed in all neonates is not clear.

Adgebite et al. described the findings on cranial ultrasound in 20 TTTS pregnancies treated with amnioreduction [18]. They found a $38 \%(15 / 40)$ incidence of periventricular white matter lesions in TTTS survivors. Of the 15 infants with white matter lesions, 6 (40\%) died in the early infancy.

Lenclen et al. reported a similar high incidence $(38 \%, 11 /$ 29) of severe cerebral injury in TTTS survivors treated with amnioreduction. PVL was detected in nine infants and IVH grade III-IV in five infants. The incidence of cerebral injury
Table 2 Cerebral injury in TTTS treated with fetoscopic laser surgery

\begin{tabular}{|c|c|c|}
\hline Author, year & $\begin{array}{l}\text { Cerebral injury } \% \\
(\mathrm{n} / \mathrm{N})\end{array}$ & Comments \\
\hline Hecher 1999 [13] & $6 \%(5 / 89)$ & $\begin{array}{l}\text { Cystic PVL, IVH } \geq \text { grade III and parenchymal defect } \\
\text { (no further details on exact numbers) }\end{array}$ \\
\hline Quintero 2003 [17] & $3 \%(4 / 136)$ & No details provided \\
\hline Senat $2004[8]$ & $6 \%(10 / 144)^{*}$ & Cystic PVL $\geq$ grade III $(n=8), \mathrm{IVH} \geq$ grade III $(n=2)$ \\
\hline Lenclen 2007 [19] & $16 \%(16 / 99)$ & Cystic PVL $(n=10)$, IVH $\geq$ grade III $(n=7)$ \\
\hline Cincotta 2009 [9] & $3 \%(4 / 143)$ & Cystic PVL $(n=2)$; other severe cerebral injury not specified \\
\hline Vanderbilt 2012 [24] & $7 \%(18 / 242)$ & $\begin{array}{l}\text { Cystic PVL }(n=7) \text {; ventriculomegaly }(n=6) ; \text { IVH } \geq \text { grade III } \\
\quad(n=6) ; \text { porencephalic cyst }(n=1)\end{array}$ \\
\hline Spruijt $2012[25 \bullet \bullet]$ & $9 \%(23 / 267)$ & $\begin{array}{l}\text { Cystic PVL }(n=7) \text {; ventriculomegaly }(n=8) ; \text { IVH } \geq \text { grade III } \\
(n=19) \text {; arterial stroke }(n=4) \text {; venous hemorrhagic infarction } \\
\text { of right temporal lobe with parenchymal loss }(n=1)\end{array}$ \\
\hline Range & $3-16 \%$ & \\
\hline
\end{tabular}

\footnotetext{
*The denominator is the total number of fetuses (and not the number of live-born infants).
} 
was significantly higher compared with a control group of dichorionic twins as well as a group of TTTS survivors treated with laser surgery [19].

Hyodo et al. reported an incidence of $15 \%(5 / 34)$ of cystic PVL in a TTTS cohort treated conservatively, without amnioreduction [20]. Strikingly, all cases with severe cerebral injury were recipients. This similar association between recipient status and cerebral injury was confirmed by Haverkamp et al. Of the 40 long-term survivors, $22.5 \%(9 / 40)$ had severe cerebral injury (grade III-IV IVH, $n=3$; cystic PVL, $n=5$; infarct, $n=1)$ [21]. Eight of the nine (89\%) infants with cerebral injury were recipients.

According to Rodeck et al., the increased risk of cerebral injury in recipients in TTTS pregnancies treated with amnioreduction could be due to the "placental steal phenomenon" [22]. Removal of large volumes of amniotic fluid may lead to a significant and rapid change in amniotic fluid pressure and shift in fetoplacental blood volume. This "placental steal effect" may lead to acute hypovolemia and hypotensive shock in the recipient.

\section{Cerebral Injury in TTTS Treated with Laser Surgery}

The reported incidence of cerebral injury after laser surgery ranges from $3 \%$ to $16 \%$ (Table 2). In a study from Hecher, $6 \%(5 / 89)$ of surviving neonates had an abnormal ultrasound scan [13]. Abnormal scans included cystic PVL, IVH $\geq$ grade III, parenchymal defects, and microcephaly. However, further details on the exact number were not reported.

Quintero et al. reported an incidence of neurologic morbidity in only $3 \%(4 / 136)$ of TTTS survivors after laser surgery [17]. Detailed information on cerebral injury was not reported in this study, limiting the interpretation of the results.

In 2006, we reported on the incidence of severe cerebral injury in 84 TTTS live-born infants treated with laser compared with a control group of 108 monochorionic twins without TTTS [1]. We found a $14 \%(12 / 84)$ incidence of cerebral injury compared with $6 \%(6 / 108)$ in the control group $(p=0.04)$. Antenatal injury was responsible for cerebral injury in $67 \%(8 / 12)$ of the TTTS group.

In a study in 143 TTTS survivors from Cincotta et al., the authors reported an extremely low rate of only $3 \%$ of severe cerebral abnormalities [9]. In this study, cranial ultrasound scans were only performed routinely in infants with birth weight $<1,500 \mathrm{~g}$ or in larger infants when "clinically indicated." Importantly, cerebral lesions in survivors (whether $<32$ weeks' gestation or birth weight $<1,500 \mathrm{~g}$ ) are usually clinically "silent" in the neonatal period and may only be detected at a later age, after neurological deficits appear. Therefore, defining clinical indications to perform cranial ultrasound in "non-high-risk" TTTS survivors will not lead to a reliable regimen and cerebral lesions will then be missed.
In a recent study in 99 TTTS survivors, Lenclen et al. reported a higher rate $(16 \%)$ of cerebral lesions after laser [19]. Only TTTS survivors delivered before 34 weeks' gestation were included in this study cohort, leading to a higher rate of prematurity and possibly an increased risk for cerebral injury. Lower gestational age at birth is known to be one of the strongest predictor for cerebral injury in neonates and adverse long-term neurodevelopmental outcome [23].

In another recent large study from Vanderbilt et al., the authors reported an incidence of $7 \%$ (18/242) of severe cerebral lesions among TTTS survivors after laser. Delivery $<32$ weeks' gestation and $<28$ weeks' gestation were associated with increased likelihood of any cerebral lesion (odds ratio (OR): 4.95; $p<0.001$ and OR: $6.25 ; p<0.001$, respectively) [24]. Importantly, imaging was routinely performed only in "highrisk survivors," defined as those delivered at $<32$ weeks' gestation, and by clinical indications if born later.

We recently published the largest study to date on cerebral injury using cranial ultrasound [25••]. We evaluated the outcome in 267 neonates with TTTS treated with laser surgery treated at our center compared with a control group of dichorionic twins matched for gestational age at birth The incidence of severe cerebral lesions in the TTTS group and control group was similar, $9 \%(23 / 267)$ and $7 \%(18 / 267)$, respectively $(p=0.44)$, suggesting that TTTS survivors after laser surgery are not at increased risk for cerebral injury compared to matched dichorionic controls. Multivariable analysis revealed that only low gestational age at birth was independently associated with increased risk for severe cerebral lesions (OR: 1.35 for each week; $95 \%$ confidence interval (CI): 1.14$1.59 ; p<0.01)$, suggesting that cerebral injury is independently associated with prematurity. In contrast to dichorionic twins, cerebral injury in TTTS was already detected at birth $(52 \%$ compared with $17 \%$ in the control group; OR: $8.00 ; 95 \% \mathrm{CI}$ : $1.42-45.06 ; p=0.02$ ), showing that most cerebral injury in twins with TTTS treated with laser results from antenatal damage.

An additional finding in this study was that the incidence of cerebral lesions in the TTTS group was lower (9\%) compared with a previous study performed in the first cohort of TTTS survivors born and examined at our center [1]. The incidence of severe cerebral lesions in TTTS survivors in the first cohort was $14 \%$ [1]. The methodology (consisting of an intensive ultrasound regimen of almost weekly ultrasound scans until term age) and definitions for severe cerebral lesions used in both studies were similar. We therefore speculate that the lower incidence of cerebral injury detected in the most recent study could be related to the learning curve associated with improvement in laser surgery treatment [26].

Given the increased risk of cerebral injury, cranial ultrasound scans should be performed routinely in all TTTS survivors at birth (regardless of the type of antenatal treatment). Nevertheless, although the predictive value of sequential cranial ultrasound and/or other imaging techniques, such as MRI, 
for detecting neurologic morbidity is increasing, the predictive accuracy of cerebral imaging for neurodevelopmental outcome remains controversial [11]. Presence of long-term neurodevelopmental impairment can only reliably be ascertained by accurate and adequate long-term evaluation up until childhood.

\section{Long-Term Neurodevelopmental Outcome in TTTS Survivors}

Advancing techniques, increasing survival rates and improving short-term outcome, necessitate a greater knowledge on the impact of TTTS and its management on long-term neurodevelopment. A better understanding of the impact on child development over time will allow more accurate counseling of parents and targeted interventions to optimize child development when needed. This requires international collaboration, to obtain large enough sample sizes and statistical power, using a standardized follow-up regimen, including uniform and clearly defined criteria for long-term neurodevelopmental impairment (NDI). NDI is a standard composite outcome defined as at least one of the following: cerebral palsy (CP), severe motor developmental delay $(<2$ SD below the population mean), severe cognitive developmental delay $(<2$ SD below the population mean), bilateral blindness, or deafness requiring amplification with hearing aids. Determining NDI involves a follow-up regimen that includes a physical and neurologic examination and an assessment of cognitive and motor development using developmental tests such as the Bayley Scales of Infant and Toddler Development by certified examiners.

The incidence and type of neurodevelopmental impairment in TTTS survivors treated with amnioreduction or laser surgery reported in the literature is described in the two subchapters below and summarized in Tables 3 and 4 . Of note, and in line with the previous reported studies on cerebral injury, the extreme heterogeneity between the follow-up studies (in terms of different definitions for NDI, different follow-up regimens, and various other methodological discordances) precluded the possibility of adding up all the numbers and prevented the calculation of an overall incidence.

\section{Long-Term Neurodevelopmental Outcome in TTTS Treated with Amnioreduction}

The reported incidence of $\mathrm{CP}$ after amnioreduction ranges from $13 \%$ to $23 \%$ except for two studies, reporting a $5 \%(2 / 42)$ and $6 \%(3 / 52)$ incidence of CP [16,27]. These exceptions are probably due to underreporting, because the diagnosis of $\mathrm{CP}$ in these studies was solely based on clinical records in the first, whereas only children born $<33$ weeks' gestational age or where questionnaires indicated deficits underwent neurologic examination in the latter. The incidence of NDI in TTTS after amnioreduction reported in the literature varies even more, ranging from $6 \%$ to $26 \%[2,14,16,21,27-30]$. This large discrepancy is probably due to considerable differences in methodology between the studies and heterogeneity within the case series. In addition, in the majority of studies, cohorts included only a small number of children (range 20-52 children) without appropriate comparison groups. As a consequence, studies were unable to assess whether NDI was due to confounders such as prematurity or low birth weight [8]. Finally, not all studies included standardized developmental tests $[2,16,29,30]$. Table 3 summarizes the follow-up studies after amnioreduction.

As reported previously, the neurologic outcome in the Eurofetus trial of TTTS survivors treated with laser was more favorable compared to amnioreduction [8]. However, followup in a subgroup of children included in the trial showed similar rates of long-term impairment [31]. The results of this follow-up study were however limited. A clear definition of impairment, in terms of NDI, was not reported neither detailed information on individual observations of impairment. Furthermore, the outcome data were confounded by an extremely high rate of deaths in the group of neonates treated with amnioreduction, probably related to withdrawal of intensive care treatment due to severe cerebral injury. The missing information is crucial to put the results into perspective. As reported in the Eurofetus trial, $22 \%$ (20/93) of the live-born neonates in the amnioreduction group had severe cystic PVL ( $\geq$ grade III) [8]. Because neonatal death rate and withdrawal of intensive-care-treatment in children with severe cerebral injury are strongly correlated with each other, long-term outcome results must be interpreted with care. The rate of $\mathrm{CP}$ and/ or NDI in the amnioreduction group could have been much higher, had these severely damaged children survived.

\section{Long-Term Neurodevelopmental Outcome in TTTS Treated with Laser Surgery}

The reported the incidence of $\mathrm{CP}$ after laser surgery ranges from $3 \%$ to $12 \%[5,33-36,37 \bullet \cdot]$ and the incidence of NDI ranges from $7 \%$ to $18 \%[5,23,33-36,38,39]$. Table 4 summarizes the follow-up studies after laser surgery. In 1999, De Lia et al. reported a $5 \%$ (5/93) incidence of major impairment in TTTS survivors after laser surgery [33]. However, mean age at follow-up was 14 months, which is too early for a reliable diagnosis of $\mathrm{CP}$ or developmental delay. In addition, no developmental tests were performed. Sutcliffe et al. found CP in $9 \%(6 / 66)$ of TTTS survivors treated with laser [34]. In $47 \%(31 / 66)$ of survivors outcome was assessed using information from their general practitioner. In the group assessed by a pediatrician, $14 \%(5 / 36)$ had CP. Although the children assessed by a pediatrician were also tested with a standardized developmental test, details on the number of children with 
Table 3 Long-term neurodevelopmental outcome in TTTS treated with amnioreduction

\begin{tabular}{|c|c|c|c|c|}
\hline Author, year & Outcome measure & $\mathrm{CP} \%(\mathrm{n} / \mathrm{N})$ & $\begin{array}{l}\text { NDI \% } \\
(\mathrm{n} / \mathrm{N})\end{array}$ & Comments \\
\hline Reisner 1993 [30] & Neurologic exam & $18 \%(7 / 39)$ & n.a. & $\begin{array}{l}\text { No developmental tests, no controls, } \\
n=19<18 \text { months }\end{array}$ \\
\hline Mari $2000[16]$ & $\begin{array}{l}\text { Clinical record, discussion parent or } \\
\text { pediatrician, speech or physical therapy }\end{array}$ & $5 \%(2 / 42)$ & n.a. & $\begin{array}{l}\text { No developmental tests, inclusion of } \\
\text { mild TTTS cases, follow-up based } \\
\text { on clinical records, no controls, } \\
\text { high NND rate }(16 \%)\end{array}$ \\
\hline Cincotta $2000[14]$ & $\begin{array}{l}\text { Neurological examination, physiotherapy } \\
\text { assessment, Griffiths Scale }\end{array}$ & $13 \%(3 / 23)$ & $22 \%(5 / 23)$ & $\begin{array}{l}\text { High NND rate }(18 \%) \text {, the inclusion } \\
\text { of gestation matched twin controls }\end{array}$ \\
\hline Haverkamp 2001 [21] & $\begin{array}{l}\text { Neurological examination, Denver Screening } \\
\text { Test, Griffiths Scale }\end{array}$ & $23 \%(9 / 40)$ & $23 \%(9 / 40)$ & $\begin{array}{l}\text { High lost-to-follow-up rate }(18 \%) \text {, } \\
\text { incomplete follow-up, no controls }\end{array}$ \\
\hline Frusca 2003 [28] & Neurological examination, Griffiths Scale & $16 \%(5 / 31)$ & $26 \%(8 / 31)$ & $\begin{array}{l}35 \%(11 / 31) \text { of children were }<2 \text { years } \\
\text { at time of follow-up, no controls }\end{array}$ \\
\hline Lopriore 2003 [2] & Neurological examination, school functioning & $21 \%(6 / 29)$ & n.a. & No developmental tests \\
\hline Dickinson 2005 [27] & $\begin{array}{l}\text { Neurological examination, General Health } \\
\text { Questionnaire, Vineland Scales, Child Behavior } \\
\text { Checklist, Bayley Scales, Stanford-Binet } \\
\text { Intelligence Scale }\end{array}$ & $6 \%(3 / 49)$ & $14 \%(7 / 49)$ & $\begin{array}{l}\text { Neurologic examination in children } \\
\text { born very preterm, minor NDI not } \\
\text { reported, behavioral outcome but } \\
\text { only in prescholars, inclusion } \\
\text { contemporaneous regional cohort }\end{array}$ \\
\hline Lenclen 2009 [29] & Neurologic examination, Ages and Stages Questionnaire & $19 \%(4 / 21)$ & n.a. & $\begin{array}{l}\text { Children not individually investigated, } \\
\text { preterm DC controls matched for } \\
\text { GA at birth, inclusion of children } \\
\text { following FLC }\end{array}$ \\
\hline Salomon 2010 [31] & $\begin{array}{l}\text { Neurologic examination, Ages and Stages } \\
\text { Questionnaire, Wechsler scales, Goodenough } \\
\text { Draw-a-Man-Test }\end{array}$ & $13 \%(6 / 47)$ & n.a. & $\begin{array}{l}\text { NDI not reported, high NND rate } \\
(22 \%) \text {, no controls, inclusion of } \\
\text { children following laser }\end{array}$ \\
\hline Li $2011[32]$ & $\begin{array}{l}\text { Neurologic examination, Enjoji Development Scale, } \\
\text { Wechsler scales }\end{array}$ & $23 \%(3 / 13)$ & $23 \%(3 / 13)$ & $\begin{array}{l}\text { Small study size, preponderance of } \\
\text { mild TTTS cases }\end{array}$ \\
\hline Range & & $5-23 \%$ & $14-26 \%$ & \\
\hline
\end{tabular}

CP, cerebral palsy; NDI, neurodevelopmental impairment, which is defined as CP, severe developmental delay ( $<2$ SD), blindness, or deafness; NND, neonatal death; DC, dichorionic.

The first part of the Eurofetus trial is not included in this table because the children are more fully described in the follow-up of this trial.

severe developmental delay were not reported. Two follow-up studies from Germany, reported an $11 \%(10 / 89)$ and $8 \%(13 /$ $167)$ incidence of NDI at 2 years of age [5,35]. NDI was more likely in twins born $<32$ weeks' gestation. In both studies, the definition of impairment did not include severe developmental delay. Hence, children with severe developmental delay but without CP were not included in the group with NDI. Neurodevelopmental outcome of 190 of these 256 children was reevaluated at a median age of 6 years and 5 months [38]. With 82 children, the K-Assessment Battery for children (K$\mathrm{ABC}$ ) was performed, a standardized intelligence test. NDI, defined as major neurologic deficiencies, such as $\mathrm{CP}$ and severe cognitive developmental delay as measured with the $\mathrm{K}-\mathrm{ABC}$, was detected in $9 \%(17 / 190)$. The authors conclude that neurodevelopmental outcome at 6 years was not different from outcome at 2 years. Of note, a significant higher rate of children with NDI was born very or extremely preterm compared with the children with normal development.

In a long-term follow-up study in France, Lenclen et al. report an incidence of NDI of $11 \%(10 / 88)(\mathrm{CP}: n=9$; blindness: $n=1)$
[29]. Developmental test scores were similar in TTTS survivors compared with preterm dichorionic twins. According to the authors, developmental delay might have been underestimated since development was investigated with the Ages and Stages Questionnaire (ASQ), which is a parent-completed screening tool [40]. Low gestational age at birth appeared significantly associated with NDI (relative risk (RR): 1.2 for each week; $95 \%$ CI: $1.1-1.4 ; p=0.02)$. In 2009, three European fetal therapy centers (Barcelona, Leuven, and Leiden) performed a multicenter follow-up study to investigate the risk factors for NDI in TTTS treated with laser [23]. Long-term outcome data, including standardized developmental test results, were collected in 278 TTTS survivors. CP was diagnosed in $6 \%$ of children (17/ 278). Severe cognitive developmental delay was diagnosed in $7 \%(19 / 278)$ and severe motor developmental delay in $12 \%$ (34/278). Two children had bilateral blindness (1\%) and two other had bilateral deafness (1\%). Overall, the incidence of NDI was $18 \%(50 / 278)$. Gestational age at birth was independently associated with NDI (OR: 1.33 for each week: $95 \%$ CI: 1.051.67: $p=0.016)$ [23]. Gray et al. found a $4 \%(5 / 113)$ incidence of 
Table 4 Long-term neurodevelopmental outcome in TTTS treated with laser surgery

\begin{tabular}{|c|c|c|c|c|}
\hline Author, year & Outcome measure & $\mathrm{CP} \%(\mathrm{n} / \mathrm{N})$ & NDI $\%(n / N)$ & Comments \\
\hline De Lia 1999 [33] & Neurologic exam & $3 \%(3 / 93)$ & n.a. & $\begin{array}{l}\text { No developmental tests, mean age at follow-up } \\
14 \text { months (1-34), no controls }\end{array}$ \\
\hline Sutcliffe 2001 [34] & Neurologic exam, Griffiths Scale & $9 \%(6 / 66)$ & $9 \%(6 / 66)$ & $\begin{array}{l}\text { High lost-to-follow-up rate (19 \%), some } \\
\text { families followed up by GP ( } 47 \% \text { ), } \\
\text { incomplete developmental tests }(54 \%) \text {, } \\
\text { no controls }\end{array}$ \\
\hline Banek 2003 [5] & $\begin{array}{l}\text { Neurologic exam, Griffiths } \\
\text { Scale, Snijders-Oomen } \\
\text { Intelligence test }\end{array}$ & $11 \%(10 / 89)$ & n.a. & $\begin{array}{l}\text { Severe developmental delay not included as } \\
\text { criterion for major disability, no controls }\end{array}$ \\
\hline Graef 2006 [35] & $\begin{array}{l}\text { Neurologic exam, Griffiths } \\
\text { Scale, Snijders-Oomen } \\
\text { Intelligence test }\end{array}$ & $6 \%(10 / 167)$ & $8 \%(13 / 167)$ & Sub-optimal/incomplete use of developmental tests \\
\hline Lenclen 2009 [29] & $\begin{array}{l}\text { Neurologic exam, Ages and Stages } \\
\text { Questionnaire }\end{array}$ & $10 \%(9 / 88)$ & n.a. & $\begin{array}{l}\text { Children not individually investigated, } \\
\text { preterm DC control subjects matched } \\
\text { for GA at birth }\end{array}$ \\
\hline Lopriore 2009 [23] & Neurologic exam, Bayley scales & $6 \%(17 / 278)$ & $18 \%(50 / 278)$ & Two TTTS-pregnancies treated $>26$ weeks' gestation \\
\hline Salomon 2010 [31] & $\begin{array}{l}\text { Neurologic exam, Ages and } \\
\text { Stages Questionnaire, Wechsler } \\
\text { scale, Goodenough Draw-a-Man-Test }\end{array}$ & $12 \%(9 / 73)$ & n.a. & NDI not reported, no controls \\
\hline Gray $2011[37 \bullet \bullet]$ & $\begin{array}{l}\text { Neurologic exam, Griffiths and } \\
\text { Bayley scales }\end{array}$ & $4 \%(5 / 113)$ & $12 \%(14 / 113)$ & $\begin{array}{l}\text { Mixed developmental tests: Griffiths scales, } \\
\text { second and third version of the Bayley scales, } \\
\text { no controls }\end{array}$ \\
\hline Chang 2012 [39] & Neurologic exam, Bayley scales & $5 \%(3 / 59)$ & $7 \%(4 / 59)$ & Small study size, corrected age at follow-up 1 year \\
\hline Graeve 2012 [38] & $\begin{array}{l}\text { Neurologic exam, K-Assessment } \\
\text { Battery, German national } \\
\text { screening exam, questionnaire } \\
\text { for parents }\end{array}$ & n.a. & $9 \%$ & $\begin{array}{l}\text { Individual observations CP and cognitive } \\
\text { not reported, different instruments to } \\
\text { measure NDI, } 89 / 190 \text { children examined } \\
\text { personally, } 82 / 190 \text { children intelligence test }\end{array}$ \\
\hline Range & & $3-12 \%$ & $7-18 \%$ & \\
\hline
\end{tabular}

CP, cerebral palsy; NDI, neurodevelopmental impairment, which is defined as CP, severe developmental delay ( $<2$ SD), blindness, or deafness; NND, neonatal death; GP, general practitioner; GA, gestational age.

One follow-up study [36] in TTTS after laser is not included in this table because the included children are more fully described in the follow-up of this study [23].

CP and NDI was diagnosed in $12 \%(14 / 113)$ of children [37••]. Four children with CP also had severe cognitive developmental delay, whereas 9 children without $\mathrm{CP}$ were diagnosed with severe cognitive developmental delay, according to standardized developmental tests. Advanced Quintero stage appeared a significant and independent risk factor for NDI (OR: 13.02; $95 \%$ CI: $1.92-88.33 ; p<0.001)$. At a corrected age of 1 year at followup, Chang et al. reported CP in $5 \%(3 / 59)$ and NDI in $7 \%(4 / 59)$ of TTTS survivors treated with laser [39]. Univariate analyses revealed that low gestational age at birth was a significant predictor of impairment (OR: 0.63; $95 \%$ CI not reported; $p=0.018$ ). Although standardized neurological assessment and developmental tests were employed, the timing of follow-up was too early for a reliable diagnosis of $\mathrm{CP}$ or developmental delay.

\section{Conclusions}

TTTS is associated with an increased risk of neonatal mortality and morbidity. Considering the high incidence of cerebral injury, serial neonatal cranial ultrasound scans and careful neurodevelopmental follow-up are strongly advised in all surviving twins to rule out severe neurological disabilities. Increased awareness may improve neonatal and pediatric care for these children.

The incidence of NDI in TTTS treated with amnioreduction is high. Long-term neurodevelopmental outcome of TTTS survivors treated with laser appears more favorable. The association between low gestational age at birth and NDI may not be surprising, as prematurity is a well recognized risk factor for adverse neurodevelopmental outcome. However, special care must be taken when comparing the results of long-term follow-up studies, as discrepancy may be due to different methodology, differences in neonatal death rates, considerable heterogeneity within small case series and lack of uniform outcome criteria. All in all, regardless of antenatal treatment, all survivors are at risk for NDI and require long-term follow-up. The age of follow-up assessment in most studies is 2 years which is still of limited value, because developmental problems 
often become more apparent at a later age, especially at school age. Therefore, follow-up until at least school age is recommended. Last, continuing close collaboration between obstetricians and neonatologists is crucial to improve care of infants with TTTS.

\section{Key Guidelines}

- TTTS survivors are at increased risk for cerebral injury (mostly cystic PVL) and require accurate follow-up neuroimaging investigations after birth.

- The incidence of NDI in TTTS treated with amnioreduction is high. Long-term neurodevelopmental outcome of TTTS survivors treated with laser surgery appears more favorable.

- Low gestational age at birth in TTTS is associated with an increased risk for cerebral injury and long-term neurodevelopmental impairment.

\section{Research Directions}

- Detailed and sequential imaging studies (including fetal MRI studies) may shed more light on the timing, incidence and risk factors of cerebral injury in TTTS treated with and without laser surgery.

- Long-term follow-up studies (at least until school age), including larger numbers of TTTS survivors treated with and without laser surgery, are needed to determine the incidence and risk factors for NDI.

- To enable valid comparisons between follow-up studies, uniform and clearly defined criteria for neurodevelopmental impairment, including formal psychological testing with standardized measures, are necessary.

- Future research should take in to account more subtle abnormalities, because cognitive functioning of $1 \mathrm{SD}$ below the mean, behavioral problems, and learning difficulties already have a significant impact on care requirements and the child's future socioeconomic potential.

\section{Compliance with Ethics Guidelines}

Conflict of Interest Jeanine M. M. van Klink, Hendrik M. Koopman, Sylke J. Steggerda, Dick Oepkes, Monique Rijken, and Enrico Lopriore declare that they have no conflict of interest.

Human and Animal Rights and Informed Consent This article does not contain any studies with human or animal subjects performed by any of the authors.

\section{References}

Papers of particular interest, published recently, have been highlighted as:

•- Of importance

1. Lopriore $\mathrm{E}$ et al. Incidence, origin, and character of cerebral injury in twin-to-twin transfusion syndrome treated with fetoscopic laser surgery. Am J Obstet Gynecol. 2006;194:1215-20.

2. Lopriore $\mathrm{E}$ et al. Long-term neurodevelopmental outcome in twin-to-twin transfusion syndrome. Am J Obstet Gynecol. 2003;189:1314-9.

3. Steggerda $S$ et al. Twin-to-twin transfusion syndrome, vein of galen malformation, and transposition of the great arteries in a pair of monochorionic twins: coincidence or related association? Pediatr Dev Pathol. 2006;9:52-5.

4. Sugama S, Kusano K. Monozygous twin with polymicrogyria and normal co-twin. Pediatr Neurol. 1994;11:62-3.

5. Banek CS et al. Long-term neurodevelopmental outcome after intrauterine laser treatment for severe twin-twin transfusion syndrome. Am J Obstet Gynecol. 2003;188:876-80.

6. Benders MJ et al. Perinatal arterial stroke in the preterm infant. Semin Perinatol. 2008;32:344-9.

7. Miller V. Neonatal cerebral infarction. Semin Pediatr Neurol. 2000;7:278-88.

8. Senat MV et al. Endoscopic laser surgery versus serial amnioreduction for severe twin-to-twin transfusion syndrome. $\mathrm{N}$ Engl J Med. 2004;351:136-44.

9. Cincotta RB et al. Selective fetoscopic laser ablation in 100 consecutive pregnancies with severe twin-twin transfusion syndrome. Aust N Z J Obstet Gynaecol. 2009;49:22-7.

10. de Vries LS et al. Ultrasound abnormalities preceding cerebral palsy in high-risk preterm infants. J Pediatr. 2004;144:815-20.

11. de Vries LS et al. Myth: cerebral palsy cannot be predicted by neonatal brain imaging. Semin Fetal Neonatal Med. 2011;16:279-87.

12. Denbow ML et al. Neonatal cranial ultrasonographic findings in preterm twins complicated by severe fetofetal transfusion syndrome. Am J Obstet Gynecol. 1998;178:479-83.

13. Hecher $\mathrm{K}$ et al. Endoscopic laser surgery versus serial amniocenteses in the treatment of severe twin-twin transfusion syndrome. Am J Obstet Gynecol. 1999;180:717-24.

14. Cincotta RB et al. Long term outcome of twin-twin transfusion syndrome. Arch Dis Child Fetal Neonatal Ed. 2000;83:F171-6.

15. Dickinson JE, Evans SF. Obstetric and perinatal outcomes from the Australian and New Zealand twin-twin transfusion syndrome registry. Am J Obstet Gynecol. 2000;182:706-12.

16. Mari $\mathrm{G}$ et al. Long-term outcome in twin-twin transfusion syndrome treated with serial aggressive amnioreduction. Am J Obstet Gynecol. 2000;183:211-7.

17. Quintero RA et al. Stage-based treatment of twin-twin transfusion syndrome. Am J Obstet Gynecol. 2003;188:1333-40.

18. Adegbite AL et al. Prevalence of cranial scan abnormalities in preterm twins in relation to chorionicity and discordant birth weight. Eur J Obstet Gynecol Reprod Biol. 2005;119:47-55.

19. Lenclen $\mathrm{R}$ et al. Neonatal outcome in preterm monochorionic twins with twin-to-twin transfusion syndrome after intrauterine treatment with amnioreduction or fetoscopic laser surgery: comparison with dichorionic twins. Am J Obstet Gynecol. 2007;196:450-7.

20. Hyodo HM et al. Myocardial hypertrophy of the recipient twins in twin-to-twin transfusion syndrome and cerebral palsy. International Journal of Gynecology \& Obstetrics. 2002;80:29-34.

21. Haverkamp F et al. Neurodevelopmental risks in twin-to-twin transfusion syndrome: preliminary findings. Eur J Paediatr Neurol. 2001;5:21-7. 
22. Rodeck CH et al. Hypothesis: the placental 'steal' phenomenon - a possible hazard of amnioreduction. Fetal Diagn Ther. 2006;21:302-6.

23. Lopriore E et al. Risk Factors for Neurodevelopment Impairment in Twin-Twin Transfusion Syndrome Treated With Fetoscopic Laser Surgery. Obstet Gynecol. 2009;113:361-6.

24. Vanderbilt D et al. Prevalence and risk factors of cerebral lesions in neonates after laser surgery for twin-twin transfusion syndrome. Am J Obstet Gynecol. 2012;207:320-el-6.

25. - Spruijt M, et al. Cerebral Injury in twin-twin transfusion syndrome treated with fetoscopic laser surgery. Obstet Gynecol 2012;120:15-20. This is the largest study comparing the incidence of cerebral injury in TTTS treated with laser and dichorionic twins matched for gestational age at birth. Results suggest that survivors after laser surgery are not at increased risk for cerebral injury. Results also show a reduction in the incidence of cerebral injury in the last decade, suggesting that outcome in TTTS may have improved over time.

26. Papanna R et al. Use of the Learning Curve-Cumulative Summation test for quantitative and individualized assessment of competency of a surgical procedure in obstetrics and gynecology: fetoscopic laser ablation as a model. Am J Obstet Gynecol. 2011;204:218-9.

27. Dickinson JE et al. The long term neurologic outcome of children from pregnancies complicated by twin-to-twin transfusion syndrome. BJOG. 2005;112:63-8.

28. Frusca T et al. Pregnancies complicated by Twin-Twin transfusion syndrome: outcome and long-term neurological follow-up. Eur $\mathrm{J}$ Obstet Gynecol Reprod Biol. 2003;107:145-50.

29. Lenclen $R$ et al. Neurodevelopmental outcome at 2 years in children born preterm treated by amnioreduction or fetoscopic laser surgery for twin-to-twin transfusion syndrome: comparison with dichorionic twins. Am J Obstet Gynecol. 2009;201:291-5.

30. Reisner DP et al. Stuck twin syndrome: outcome in thirty-seven consecutive cases. Am J Obstet Gynecol. 1993;169:991-5.

31. Salomon LJ et al. Long-term developmental follow-up of infants who participated in a randomized clinical trial of amniocentesis vs laser photocoagulation for the treatment of twin-to-twin transfusion syndrome. Am J Obstet Gynecol. 2010;203:444-7.

32. Li X, Morokuma S, Fukushima K, Otera Y, Yumoto Y, Tsukimori K, et al. Prognosis and long-term neurodevelopmental outcome in conservatively treated twin-to-twin transfusion syndrome. BMC Pregnancy Childbirth. 2011;11:32. doi:10.1186/1471-2393-11-32.

33. De Lia JE, Kuhlmann RS, Lopez KP. Treating previable twin-twin transfusion syndrome with fetoscopic laser surgery: outcomes following the learning curve. J Perinat Med. 1999;27:61-7.

34. Sutcliffe AG et al. Outcome for children born after in utero laser ablation therapy for severe twin-to-twin transfusion syndrome. BJOG. 2001;108:1246-50.

35. Graef $\mathrm{C}$ et al. Long-term neurodevelopmental outcome of 167 children after intrauterine laser treatment for severe twin-twin transfusion syndrome. Am J Obstet Gynecol. 2006;194:303-8.

36. Lopriore $\mathrm{E}$ et al. Long-term neurodevelopmental outcome in twin-totwin transfusion syndrome treated with fetoscopic laser surgery. Am J Obstet Gynecol. 2007;196:231-4.

37. • Gray PH, et al. Neurodevelopmental outcome and risk factors for disability for twin-twin transfusion syndrome treated with laser surgery. Am J Obstet Gynecol 2011;204:159-6. Large long-term followup study in TTTS survivors treated with laser. Results show that survivors are at increased risk for cerebral injury and long-term neurodevelopmental impairment.

38. Graeve P et al. Neurodevelopmental outcome at 6 years of age after intrauterine laser therapy for twin-twin transfusion syndrome. Acta Paediatr. 2012;101:1200-5.

39. Chang YL et al. The neurological outcomes of surviving twins in severe twin-twin transfusion syndrome treated by fetoscopic laser photocoagulation at a newly established center. Prenat Diagn. 2012;32:893-6.

40. Skellern CY, Rogers Y, O'Callaghan MJ. A parent-completed developmental questionnaire: follow-up of ex-premature infants. J Paediatr Chilth Health. 2001;37:125-9. 